\title{
STUDY OF HIGH-TEMPERATURE THERMAL STABILITY OF MAX PHASES IN VACUUM
}

\author{
I.M. Low ${ }^{1}$, W.K. Pang ${ }^{1}$, S.J. Kennedy ${ }^{2}$, R.I. Smith ${ }^{3}$ \\ ${ }^{1}$ Centre for Materials Research, Department of Imaging and Applied Physics, Curtin University of \\ Technology, GPO Box U 1987, Perth WA, Australia \\ ${ }^{2}$ The Bragg Institute, ANSTO, PMB 1, Menai, NSW 2234, Australia \\ ${ }^{3}$ ISIS Facility, Science and Technology Facilities Council, Rutherford Appleton Laboratory, Harwell \\ Science and Innovation Campus, Didcot, Oxfordshire OX11 0QX, UK
}

\begin{abstract}
The susceptibility of two $M A X$ phases $\left(\mathrm{Ti}_{2} \mathrm{AlN}\right.$ and $\left.\mathrm{Ti}_{4} \mathrm{AlN}_{3}\right)$ to high-temperature thermal dissociation in a dynamic environment of high-vacuum has been investigated using in-situ neutron diffraction. In high vacuum, these phases decomposed above $1400^{\circ} \mathrm{C}$ through the sublimation of $\mathrm{Ti}$ and $\mathrm{Al}$ elements, forming a surface coating of TiN. The kinetics of isothermal phase decomposition was modelled using the Avrami equation and the Avrami exponent $(n)$ of isothermal decomposition of $\mathrm{Ti}_{2} \mathrm{AlN}$ and $\mathrm{Ti}_{4} \mathrm{AlN}_{3}$ was determined to be 0.62 and 0.18 respectively. The characteristics of thermal stability and phase transitions in $\mathrm{Ti}_{2} \mathrm{AlN}$ and $\mathrm{Ti}_{4} \mathrm{AlN}_{3}$ are compared and discussed.
\end{abstract}

\section{INTRODUCTION}

$M A X$ phases are nano-layered ceramics with the general formula $M_{n+1} A_{n}(n=1-3)$, where $M$ is an early transition metal, $\mathrm{A}$ is a group $\mathrm{A}$ element, and $\mathrm{X}$ is either carbon and/or nitrogen. These materials exhibit a unique combination of characters of both ceramics and metals. ${ }^{1-5}$ Like ceramics, they have low density, low thermal expansion coefficient, high modulus and high strength, and good high-temperature oxidation resistance. Like metals, they are good electrical and thermal conductors, readily machinable, tolerant to damage, and resistant to thermal shock. The unique combination of these interesting properties enables these ceramics to be a promising candidate material for use in diverse fields, especially in high temperature applications.

However, these $M A X$ phases, $\mathrm{Ti}_{3} \mathrm{SiC}_{2}$ in particular, have poor wear resistance due to low hardness ( $\sim 4 \mathrm{GPa}$ ) and are susceptible to thermal dissociation at $\sim 1400^{\circ} \mathrm{C}$ in inert environments (e.g., vacuum or argon) to form a protective surface coating of $\mathrm{TiC}^{6-11}$ Depth-profiling by x-ray diffraction of $\mathrm{Ti}_{3} \mathrm{SiC}_{2}$ annealed in vacuum at $1500^{\circ} \mathrm{C}$ has revealed a graded phase composition with more than $90 \mathrm{wt} \% \mathrm{TiC}$ on the surface and decreasing rapidly with an increase in depth. ${ }^{6,7} \mathrm{~A}$ similar phenomenon has also been observed for $\mathrm{Ti}_{3} \mathrm{AlC}_{2}$ whereby it decomposes in vacuum to form $\mathrm{TiC}$ and $\mathrm{Ti}_{2} \mathrm{AlC}$. ${ }^{10}$ It follows that this process of thermal dissociation to form protective coatings of binary carbide, nitride or carbo-nitride will also occur in other $M A X$ phases such as $\mathrm{Cr}_{2} \mathrm{GeC}, \mathrm{Ta}_{4} \mathrm{AlC}_{3}, \mathrm{Ti}_{2} \mathrm{AlN}, \mathrm{Ti}_{4} \mathrm{AlN}_{3}$ and $\mathrm{Ti}_{2} \mathrm{AlC}_{0.5} \mathrm{~N}_{0.5}$. The formation of a graded surface coating such as $\mathrm{TiC}$, TiN or TiCN has the potential to impart high hardness and wear-resistance to the otherwise soft but damage-resistant substrate. ${ }^{1,4}$

The fundamental knowledge about the thermal stability of technologically important MAX phases is still very limited and the actual process of phase dissociation is poorly understood. This limited understanding has generated much controversy concerning the high-temperature thermochemical stability of $M A X$ phases. ${ }^{12-17}$ We have recently investigated the thermal stability of $\mathrm{Ti}_{3} \mathrm{SiC}_{2}, \mathrm{Cr}_{2} \mathrm{AlC}$, $\mathrm{Ti}_{2} \mathrm{AlC}$ and $\mathrm{Ti}_{3} \mathrm{AlC}_{2}$ in vacuum at up to $1550^{\circ} \mathrm{C}$ and the results indicated 211 phases to be more resistant to phase dissociation than 312 phases. ${ }^{8-10}$ For instance, both $\mathrm{Ti}_{3} \mathrm{SiC}_{2}$ and $\mathrm{Ti}_{3} \mathrm{AlC}_{2}$ decompose readily to $\mathrm{TiC}$ forming an intermediate phase of $\mathrm{Ti}_{5} \mathrm{Si}_{3} \mathrm{C}$ and $\mathrm{Ti}_{2} \mathrm{AlC}$ respectively. The apparent activation energies for the decomposition of sintered $\mathrm{Ti}_{3} \mathrm{SiC}_{2}, \mathrm{Ti}_{3} \mathrm{AlC}_{2}$ and $\mathrm{Ti}_{2} \mathrm{AlC}$ were determined to be $179.3,-71.9$ and $85.7 \mathrm{~kJ} \mathrm{~mol}^{-1}$, respectively. ${ }^{10}$ 
Hitherto, virtually no work has been reported for ternary nitrides such as $\mathrm{Ti}_{2} \mathrm{AlN}$ and $\mathrm{Ti}_{4} \mathrm{AlN}_{3}$. It also remains unknown whether these $M A X$ phases will decompose like 211 and 312 ternary carbides via the sublimation of group $M$ element and the de-intercalation of group $A$ element as follows:

$$
M_{n+1} A X_{n} \rightarrow n M X+A+M
$$

In addition, the 413 phase is expected to form a lower order 211 phase during the initial decomposition process as follows, prior to the sublimation of $\mathrm{A}$ and $\mathrm{M}$ elements (see equation 1):

$$
\mathrm{Ti}_{4} \mathrm{AlN}_{3} \rightarrow \mathrm{Ti}_{2} \mathrm{AlN}+2 \mathrm{TiN}
$$

In this paper, we describe the use of high-temperature neutron diffraction to study the dynamic processes of phase stability of $\mathrm{Ti}_{2} \mathrm{AlN}$ and $\mathrm{Ti}_{4} \mathrm{AlN}_{3}$ in high-vacuum. The kinetics of isothermal phase decomposition was modelled using the Avrami equation and the Avrami constants were evaluated. The characteristics of thermal stability and phase transitions in $\mathrm{Ti}_{2} \mathrm{AlN}$ and $\mathrm{Ti}_{4} \mathrm{AlN}_{3}$ are compared and discussed.

\section{EXPERIMENTAL PROCEDURE}

Dense hot-pressed cylindrical bars of $\mathrm{Ti}_{2} \mathrm{AlN}$, and $\mathrm{Ti}_{4} \mathrm{AlN}$ with diameter $10 \mathrm{~mm}$ and height $20 \mathrm{~mm}$ were used for the study. The samples were not single phase but contained 6.9 and $0.8 \mathrm{wt} \% \mathrm{TiN}$. High temperature time-of-flight neutron diffraction in a vacuum furnace $\left(\sim 10^{-5}\right.$ torr $)$ fitted with tantalum elements was used to monitor the structural evolution of phase decomposition in the MAX phases from 20 to $1800^{\circ} \mathrm{C}$ in real time. A precision electronic scale with reading to five decimal places was used to measure the weight of samples before and after vacuum-decomposition at a particular temperature. Neutron diffraction data were collected using the Polaris medium resolution, high intensity powder diffractometer at the UK pulsed spallation neutron source ISIS, Rutherford Appleton Laboratory. ${ }^{18}$ The diffraction patterns were collected at $20^{\circ} \mathrm{C}$ and then at between 1500 and $1800^{\circ} \mathrm{C}$ with a heating rate of $20^{\circ} \mathrm{C} / \mathrm{min}$. The data acquisition times were $15 \mathrm{~min}$ for the room temperature diffraction pattern, and between $15-120 \mathrm{~min}$ for each of the diffraction patterns collected at elevated temperatures. Normalised data collected in the highest resolution, backscattering detector bank over the $d$-spacing range of $\sim 0.4-3.2 \AA$ were analysed using (a) the LAMP software and (b) the Full-Prof software to compute the changes in the phase content of $M A X$ phases and $M N$ during vacuum-annealing at elevated temperatures. In the former, the integrated peak intensities of lines (013) and (111) were used for calculating the relative phase content of $\mathrm{Ti}_{4} \mathrm{AlN}_{3}$ and TiN respectively. In the latter, the Rietveld method was used to compute the changes in the phase content of $\mathrm{Ti}_{2} \mathrm{AlN}$ and $\mathrm{TiN}$ during vacuumannealing.

The kinetic behaviour of the isothermal decomposition of $\mathrm{Ti}_{4} \mathrm{AlN}_{3}$ and $\mathrm{Ti}_{2} \mathrm{AlN}$ at 1500 and $1550^{\circ} \mathrm{C}$ respectively was modeled using the Avrami equation to describe the fraction of decomposed $M A X$ phase $(y)$ as a function of time $(t)$ as follows: ${ }^{19}$

$$
y(t)=y(0)+\exp \left(-k t^{n}\right)-1
$$

where $k$ and $n$ are time-independent constants for the particular reaction.

\section{RESULTS AND DISCUSSION}

\section{(a) Thermal Decomposition and Phase Transitions}

The phase evolutions of $\mathrm{Ti}_{2} \mathrm{AlN}$ and $\mathrm{Ti}_{4} \mathrm{AlN}_{3}$ at various temperatures as revealed by in-situ neutron diffraction are shown in Figures 1-3. Samples used in this experiment were not single-phase 
with $\mathrm{TiN}$ as the main impurity. $\mathrm{For} \mathrm{Ti}_{4} \mathrm{AlN}_{3}$, it began to decompose to TiN quite slowly at $1450^{\circ} \mathrm{C}$ but became more rapid above $1500^{\circ} \mathrm{C}$ (Fig. 1). It was almost completely decomposed after annealing at $1600^{\circ} \mathrm{C}$ for less than $30 \mathrm{~min}$. A total weight loss of $\sim 11.6 \%$ and $5.9 \%$ was observed for decomposition at 1600 and $1500^{\circ} \mathrm{C}$ respectively, which may be attributed to the release of gaseous $\mathrm{Al}$ and $\mathrm{Ti}$ by sublimation during the decomposition process. These results concur with our previous work on ternary carbides. ${ }^{9-12}$ However, in contrast to $\mathrm{Ti}_{3} \mathrm{AlC}$ which undergoes an intermediate decomposition to the lower order $\mathrm{Ti}_{2} \mathrm{AlC},{ }^{9-11}$ such a lower order $\mathrm{Ti}_{2} \mathrm{AlN}$ was not observed during the decomposition of $\mathrm{Ti}_{4} \mathrm{AlN}_{3}$. Nevertheless, such a decomposition process via an intermediate 211 phase cannot be completely ruled out, i.e.

$$
\begin{aligned}
& \mathrm{Ti}_{4} \mathrm{AlN}_{3} \rightarrow \mathrm{Ti}_{2} \mathrm{AlN}+2 \mathrm{TiN} \\
& \mathrm{Ti}_{2} \mathrm{AlN} \rightarrow \mathrm{TiN}+\mathrm{Al}_{(\mathrm{g})}+\mathrm{Ti}_{(\mathrm{g})}
\end{aligned}
$$

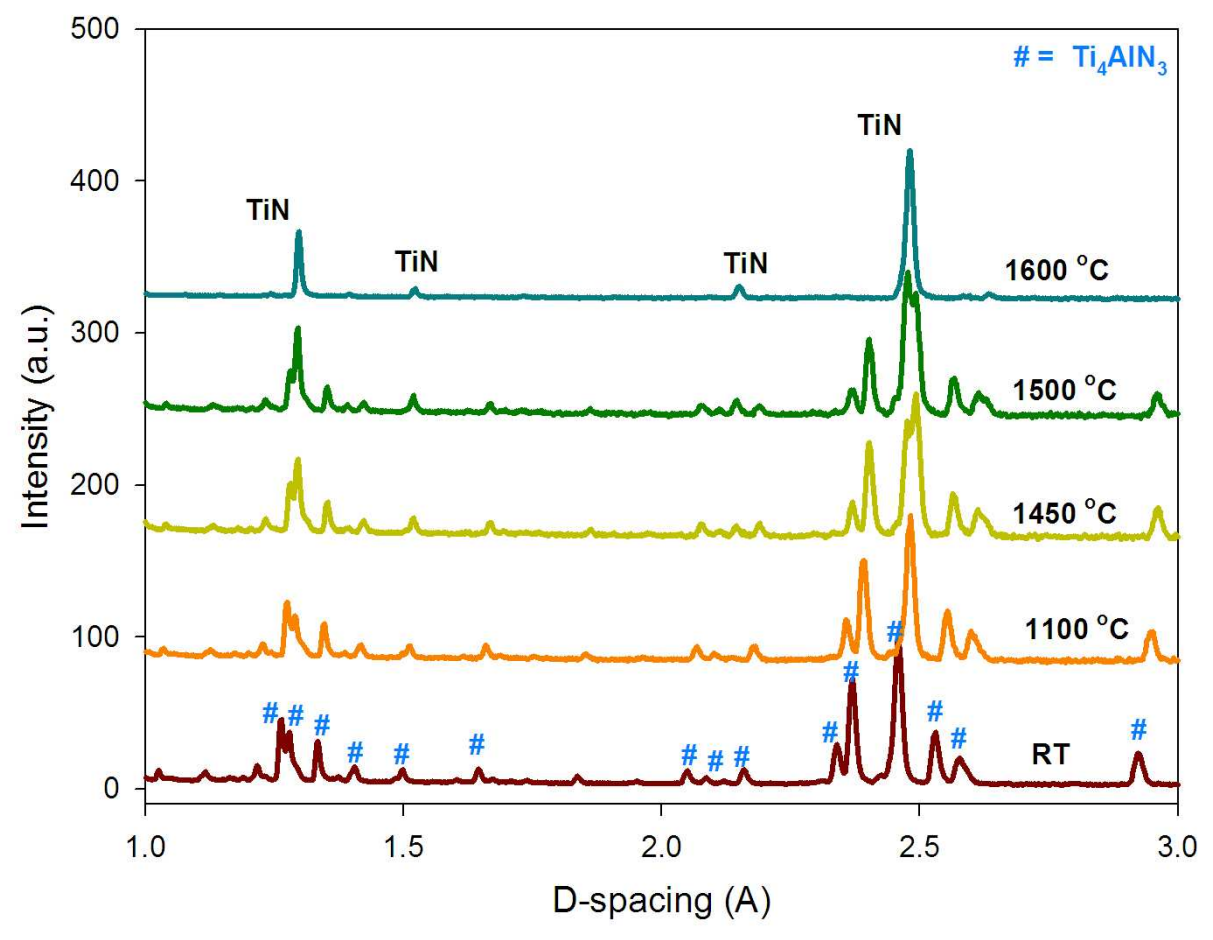

Fig. 1: Phase transitions during the decomposition of $\mathrm{Ti}_{4} \mathrm{AlN}_{3}$ at up to $1600^{\circ} \mathrm{C}$.

In spite having a higher content of $\mathrm{TiN}$ as impurity, $\mathrm{Ti}_{2} \mathrm{AlN}$ appeared to be much more stable against decomposition than $\mathrm{Ti}_{4} \mathrm{AlN}_{3}$. It began to decompose to TiN slowly after $1550^{\circ} \mathrm{C}$ but became quite rapid at $1600^{\circ} \mathrm{C}$ (Fig. 2). It was almost completely decomposed after annealing at $1700^{\circ} \mathrm{C}$ for just over 2 hours and at $1800^{\circ} \mathrm{C}$ for about $20 \mathrm{~min}$. A total weight loss of more $20.0 \%$ was observed for decomposition at $1600^{\circ} \mathrm{C}$ and above. Below $1600^{\circ} \mathrm{C}$, the weight loss was $5.0 \%$ and $0.95 \%$ at $1550^{\circ} \mathrm{C}$ and $1500^{\circ} \mathrm{C}$ respectively.

A closer look at Figure 2 shows that a new phase $\mathrm{Ti}_{4} \mathrm{AlN}_{3}$ formed when $\mathrm{Ti}_{2} \mathrm{AlN}$ was vacuumannealed at $1600^{\circ} \mathrm{C}$ and its abundance increased with time and persisted when cooled down to room 
temperature (Fig. 3). However, it disappeared when the temperature was increased to $1700^{\circ} \mathrm{C}$ and above. Possible reactions for the formation of $\mathrm{Ti}_{4} \mathrm{AlN}_{3}$ during the decomposition of $\mathrm{Ti}_{2} \mathrm{AlN}$ and its subsequent disappearance are as follows:

$$
\begin{aligned}
& 3 \mathrm{Ti}_{2} \mathrm{AlN} \rightarrow \mathrm{Ti}_{4} \mathrm{AlN}_{3}+2 \mathrm{Al}_{(\mathrm{g})}+2 \mathrm{Ti}_{(\mathrm{g})} \\
& \mathrm{Ti}_{4} \mathrm{AlN}_{3} \rightarrow \mathrm{Ti}_{2} \mathrm{AlN}+2 \mathrm{TiN} \\
& \mathrm{Ti}_{2} \mathrm{AlN} \rightarrow \mathrm{TiN}+\mathrm{Al}_{(\mathrm{g})}+\mathrm{Ti}_{(\mathrm{g})}
\end{aligned}
$$

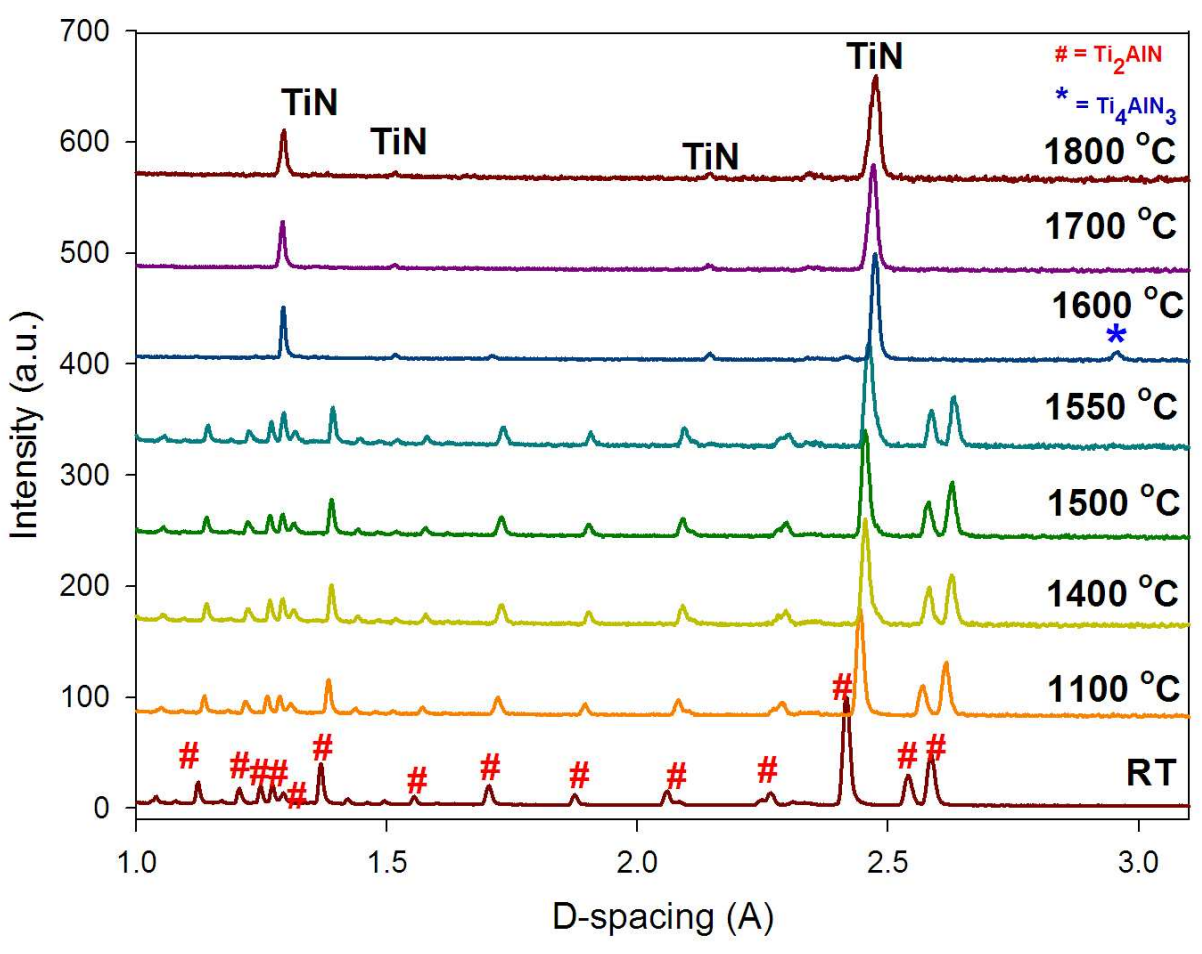

Fig. 2: Phase transitions during the decomposition of $\mathrm{Ti}_{2} \mathrm{AlN}$ at up to $1800^{\circ} \mathrm{C}$.

As previously mentioned, the weight losses of up to $6 \%$ and over $20 \%$ in decomposed $\mathrm{Ti}_{2} \mathrm{AlN}$ and $\mathrm{Ti}_{4} \mathrm{AlN}_{3}$ respectively can be attributed to the release of gaseous $\mathrm{Al}$ and $\mathrm{Ti}$ by sublimation during the decomposition process because the vapor pressures of both $\mathrm{Al}$ and $\mathrm{Ti}$ exceed the ambient pressure of the furnace (i.e. $\leq 5 \times 10^{-5}$ torr) at $\geq 1500^{\circ} \mathrm{C}^{20}$ Since the vapor pressure of a substance increases nonlinearly with temperature according to the Clausius-Clapeyron relation, ${ }^{21}$ the volatility of $\mathrm{Al}$ and Ti will increase with any incremental increase in temperature. Figure 4 shows the vapour pressures of various elements at elevated temperature and at a vapour pressure of $5 \times 10^{-5}$ torr in the vacuum furnace, $\mathrm{Al}$ and $\mathrm{Ti}$ become volatile at temperature greater than 950 and $1450^{\circ} \mathrm{C}$ respectively. Thus, at the temperature of well over $1500^{\circ} \mathrm{C}$ used in this study, both $\mathrm{Al}$ and $\mathrm{Ti}$ should become volatile and sublime readily and continuously in a dynamic environment of high vacuum. When the vapor pressure becomes sufficient to overcome ambient pressure in the vacuum furnace, bubbles will form inside the bulk of the substance which eventually appear as voids on the surface of decomposed MAX phase. ${ }^{9-12}$ 
The evidence of voids formation can be clearly discerned from the porous surface damage of decomposed $\mathrm{Ti}_{2} \mathrm{AlN}$ and $\mathrm{Ti}_{4} \mathrm{AlN}_{3}$ (Fig. 5). A closer look at Fig. 4 also explains why $\mathrm{Ti}_{3} \mathrm{SiC}_{2}$ is more resistant to decomposition than $\mathrm{Ti}_{3} \mathrm{AlC}_{2}$ or $\mathrm{Ti}_{4} \mathrm{AlN}_{3}$ because $\mathrm{Si}$ has a lower vapour pressure than $\mathrm{Al}$. Thus, the use of vapor pressure of elements such as Fig. 4 can be used to predict the susceptibility of $M A X$ phases to thermal decomposition. Alternatively, the sublimation pressure of an element can be estimated from the following equation: ${ }^{22}$

$$
\ln P_{\text {solid }}^{S}=\ln P_{\text {liquid }}^{S}-\frac{\Delta H_{m}}{R}\left(\frac{1}{T}-\frac{1}{T_{m}}\right)
$$

where $P_{\text {solid }}^{S}=$ sublimation pressure of the solid component at the temperature $T<T_{m} ; P_{\text {liquid }}^{S}=$ extrapolated vapor pressure of the liquid component at the temperature $T<T_{m} ; \Delta \boldsymbol{H}_{\boldsymbol{m}}=$ heat of fusion; $R=$ gas_constant $;=$ sublimation temperature, and $T_{m}=$ melting point temperature.

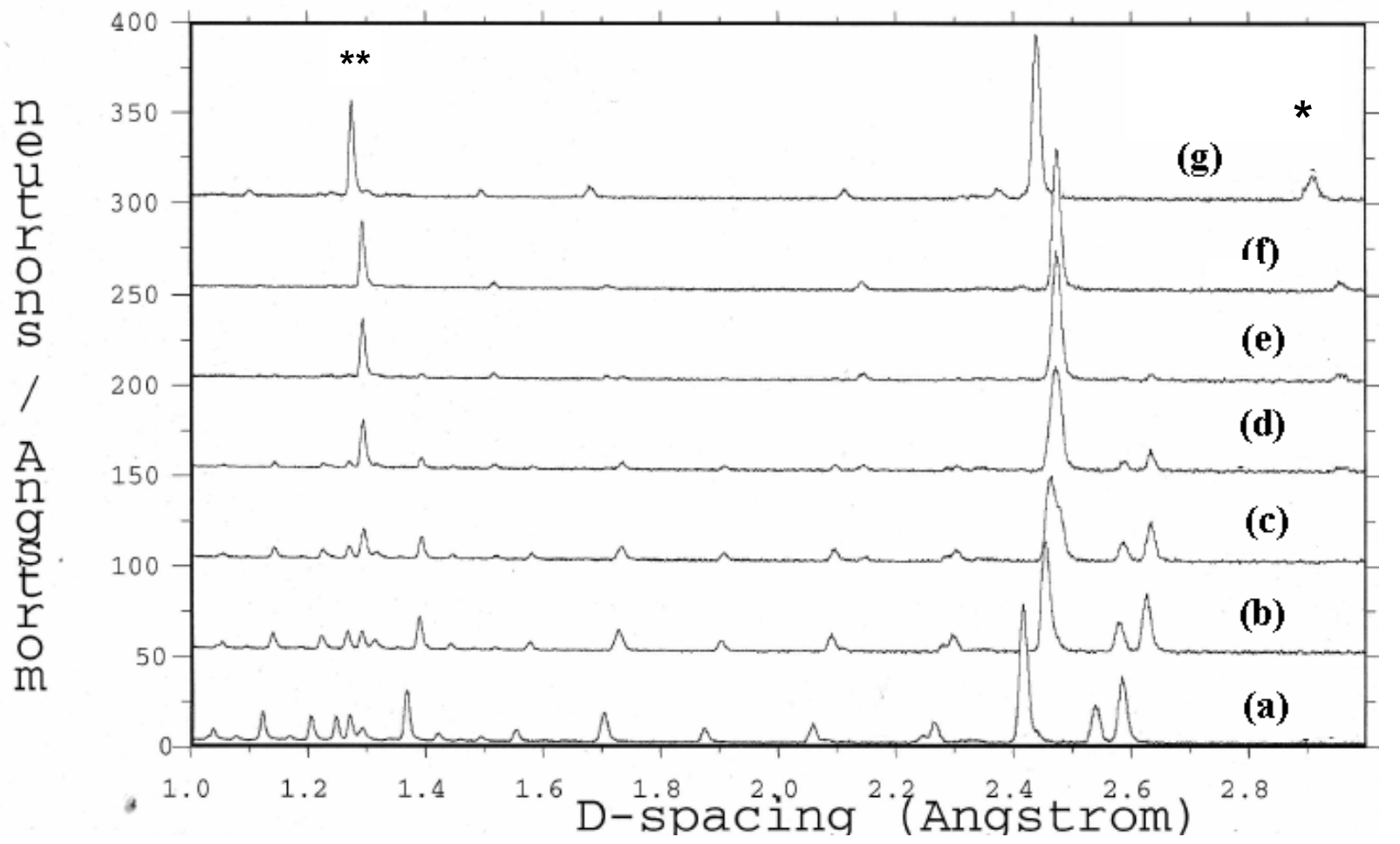

Fig. 3: Diffraction patterns of $\mathrm{Ti}_{2} \mathrm{AlN}$ vacuum annealed at: (a) $20^{\circ} \mathrm{C}$; (b) $1400^{\circ} \mathrm{C}$; (c) $1600^{\circ} \mathrm{C} / 10 \mathrm{~min}$; (d) $1600^{\circ} \mathrm{C} / 40 \mathrm{~min}$; (e) $1600^{\circ} \mathrm{C} / 80 \mathrm{~min}$; (f) $1600^{\circ} \mathrm{C} / 130 \mathrm{~min}$, and (g): Cooled to $20^{\circ} \mathrm{C}$. Note the formation of $\mathrm{Ti}_{4} \mathrm{AlN}_{3}$ at $1600^{\circ} \mathrm{C}$. [Legend: $*=\mathrm{Ti}_{4} \mathrm{AlN}_{3} ; * *=\mathrm{TiN}$ ] 


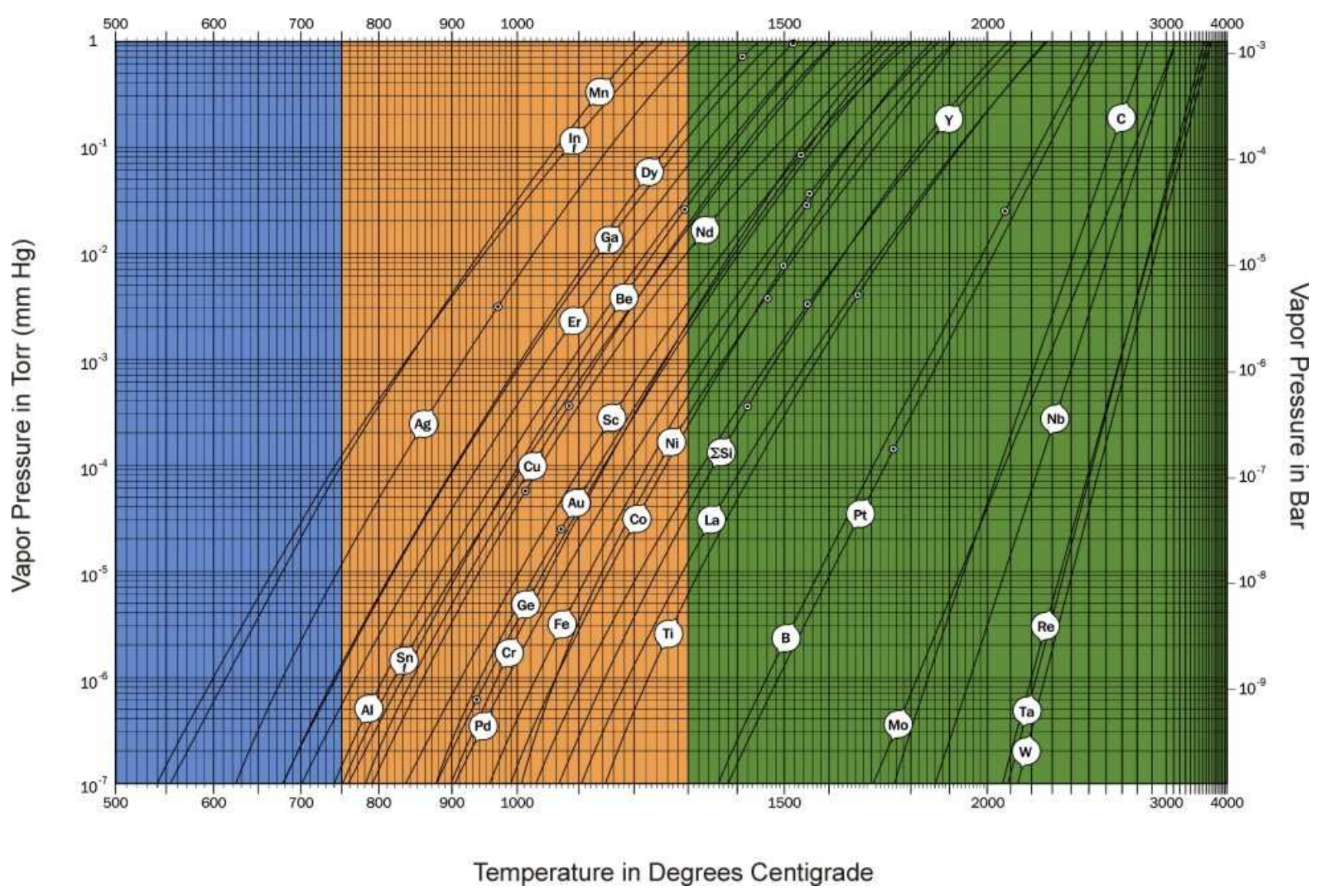

Fig. 4 Vapor pressure of elements at various temperatures. ${ }^{20}$

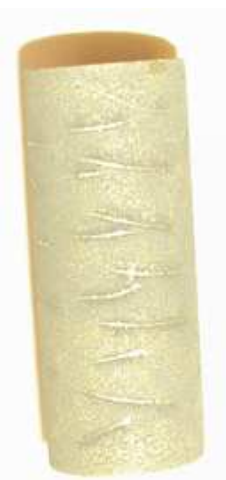

(a)

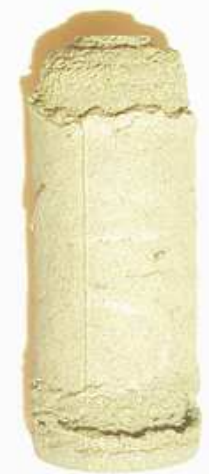

(b)

(i)

[(a) Before decomposition; (b) after decomposition at $1600^{\circ} \mathrm{C}$ for $440 \mathrm{~min}$.] 


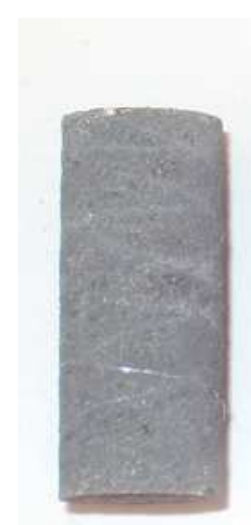

(a)

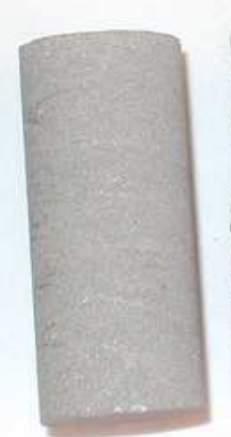

(b)

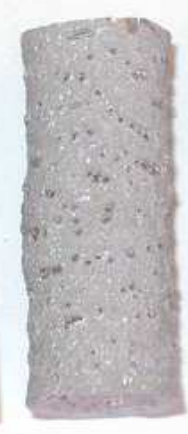

(c)

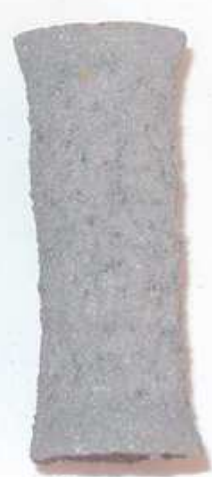

(d)

(ii)

[(a) Before decomposition; (b-d) after decomposition at $1500^{\circ} \mathrm{C} / 120 \mathrm{~min}, 1550^{\circ} \mathrm{C} / 460 \mathrm{~min} \& 1600^{\circ} \mathrm{C} / 420$ $\min ]$

Fig. 5: Surface conditions of (i) $\mathrm{Ti}_{4} \mathrm{AlN}_{3}$ and (ii) $\mathrm{Ti}_{2} \mathrm{AlN}$ before and after thermal decomposition in vacuum.

\section{(b)Isothermal Phase Decomposition and Avrami Kinetics}

Fig. 6 shows the isothermal decomposition of $\mathrm{Ti}_{4} \mathrm{AlN}_{3}$ at $1500^{\circ} \mathrm{C}$ which was quite rapid initially but slowed down significantly after 30 minutes dwell. More than $40 \%$ of $\mathrm{Ti}_{4} \mathrm{AlN}_{3}$ decomposed after vacuum annealing at $1500^{\circ} \mathrm{C}$ for 400 minutes. In contrast, the extent of decomposition for $\mathrm{Ti}_{2} \mathrm{AlN}$ was much less with only $20 \%$ decomposed after 300 minutes dwell at $1550^{\circ} \mathrm{C}$ (Fig. 7). This implies that $\mathrm{Ti}_{2} \mathrm{AlN}$ has a significantly higher resistance to thermal decomposition than $\mathrm{Ti}_{4} \mathrm{AlN}_{3}$. A possible reason for the high susceptibility of $\mathrm{Ti}_{4} \mathrm{AlN}_{3}$ to decomposition is either the existence of a lower order 211 phase or the much weaker Al-Ti bonding in this more complex layered compound where Al lies in every fifth layer. ${ }^{3}$ In contrast, every third layer in the 211 compound lies the $\mathrm{Al}$ atoms, resulting in shorter but stronger Al-Ti bonds which provides more resistance to decomposition via out-diffusion of $\mathrm{Al}$ from the bulk to the surface.

During the isothermal decomposition of 211 and 413 phases at 1550 and $1500^{\circ} \mathrm{C}$ respectively, the Avramii kinetics of decomposition was modeled using Equation (3) and the Avrami constants were evaluated. The Avrami fit of the isothermal decomposition of $\mathrm{Ti}_{4} \mathrm{AlN}_{3}$ and $\mathrm{Ti}_{2} \mathrm{AlN}$ is shown in Fig. 6 and Fig. 7 respectively. The calculated Avrami exponent (n) and Avrami constant (k) for the two MAX phases are summarized in Table 1. In general, when the value of $n$ is large (e.g. 3 or 4), a 3-dimensional nucleation and growth processes are involved. ${ }^{23}$ High values of $n$ can also occur when nucleation occurs on specific sites such as grain boundaries or impurities which rapidly saturate soon after the transformation begins. Initially, nucleation may be random and growth unhindered leading to high values for $n$. Once the nucleation sites are consumed the transformation will slow down or cease. Furthermore, if the distribution of nucleation sites is non-random then the growth may be restricted to 1 or 2-dimensions. Site saturation my lead to $n$ values of 1,2 or 3 for surface, edge and point sites, respectively. ${ }^{19}$ Since the values of $n$ obtained in this study for both 211 and 413 phases are less than 1.0 , this implies that the decomposition process is driven by highly restricted out-diffusion of aluminium from the bulk to the surface of the sample and into the vacuum. 


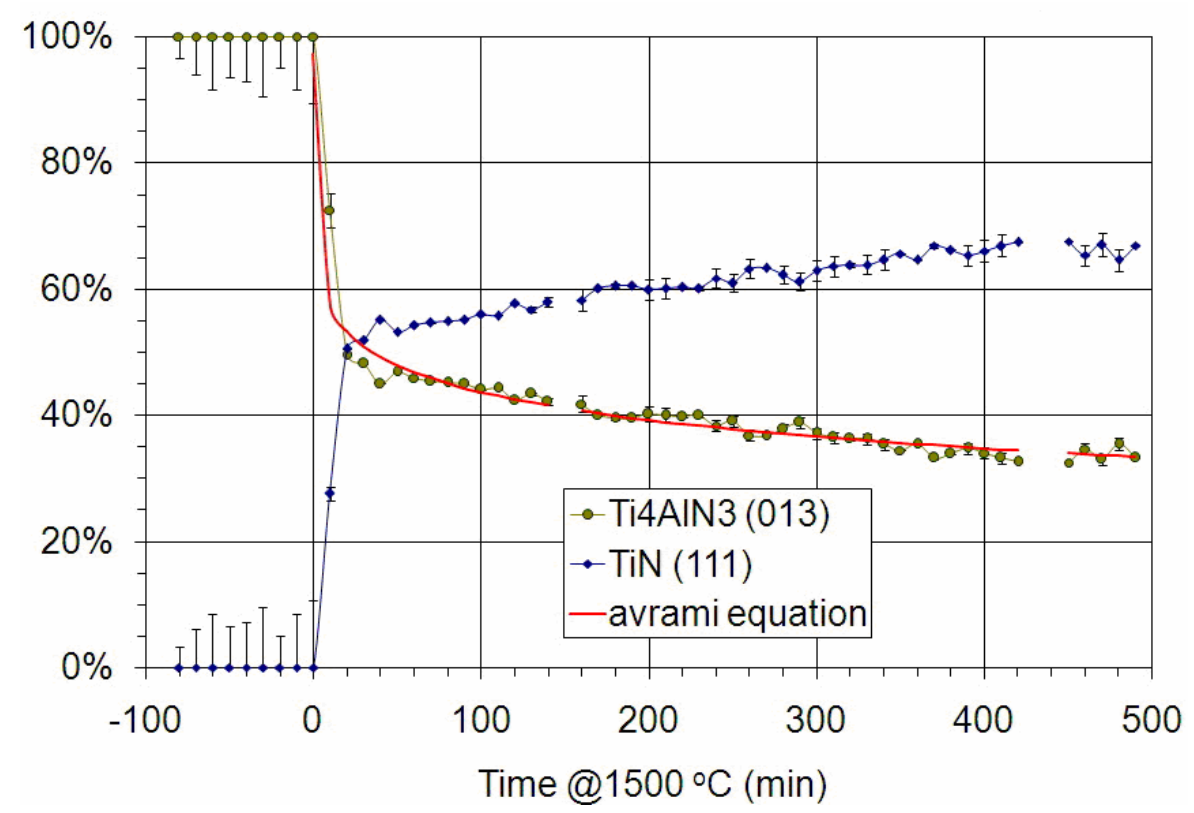

Fig. 6: Time-dependent phase abundance and Avrami fit of isothermal decomposition of $\mathrm{Ti}_{4} \mathrm{AlN}_{3}$ at $1500^{\circ} \mathrm{C}$.

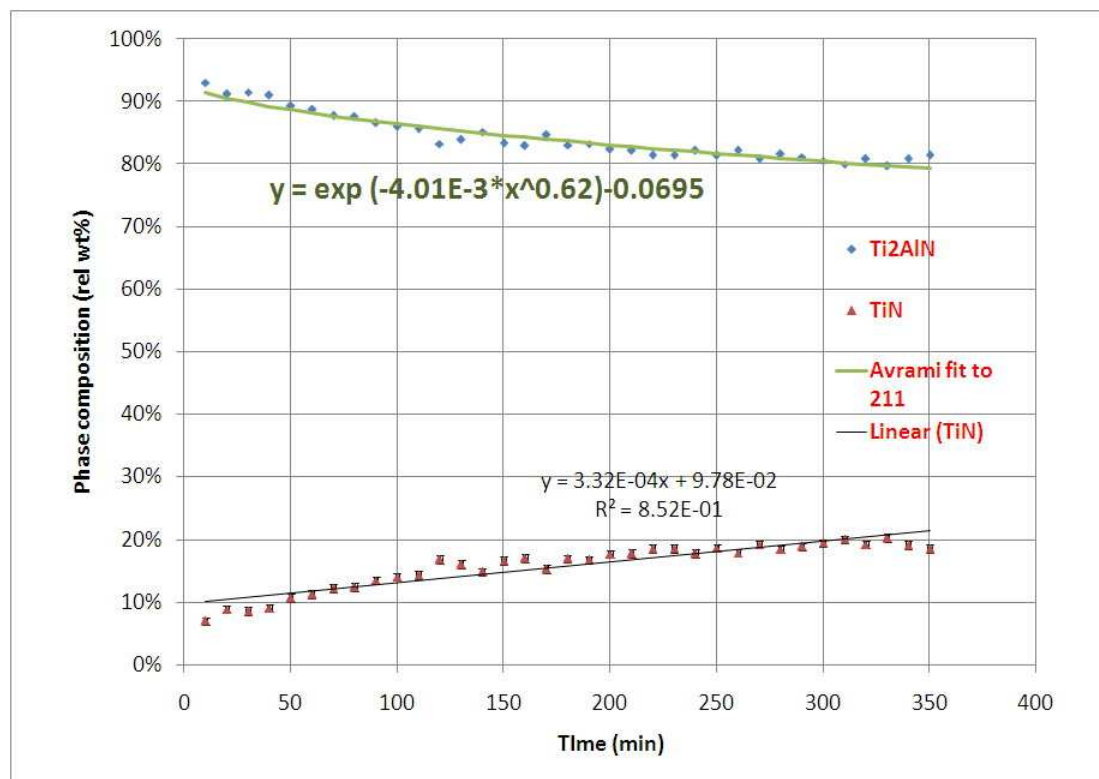

Fig. 7: Time-dependent phase abundance and Avrami fit of isothermal decomposition of $\mathrm{Ti}_{2} \mathrm{AlN}$ at $1550^{\circ} \mathrm{C}$.

Table 1. Comparison of the decomposition of MAX 211 and 413 phases.

\begin{tabular}{|c|c|c|}
\hline$M A X$ phase & Avrami exponent $(n)$ & $\begin{array}{c}\text { Avrami constant }(k) \\
\mathrm{mol} \% \cdot(\mathrm{min})^{-\mathrm{n}}\end{array}$ \\
\hline $\mathrm{Ti}_{4} \mathrm{AlC}_{3}$ & 0.18 & 0.37 \\
\hline $\mathrm{Ti}_{2} \mathrm{AlN}$ & 0.62 & $4.01 \times 10^{-3}$ \\
\hline
\end{tabular}




\section{CONCLUSIONS}

The high-temperature thermal stability of $\mathrm{Ti}_{2} \mathrm{AlN}$ and $\mathrm{Ti}_{4} \mathrm{AlN}_{3}$ in a dynamic environment of highvacuum has been studied using in-situ neutron diffraction. Both 211 and 413 phases were susceptible to decomposition above $1400^{\circ} \mathrm{C}$ through sublimation of $\mathrm{Al}$ and Ti elements, resulting in a surface coating of TiN being formed. The kinetics of isothermal phase decomposition was modelled using the Avrami equation and the Avrami constants $\left(n\right.$ and $K$ ) of isothermal decomposition of $\mathrm{Ti}_{2} \mathrm{AlN}$ and $\mathrm{Ti}_{4} \mathrm{AlN}_{3}$ were determined to be $0.62,0.18$ and $4.01 \times 10^{-3}, 0.37 \mathrm{~mol} \% \cdot(\mathrm{min})^{-\mathrm{n}}$ respectively.

\section{ACKNOWLEDGEMENTS}

This work formed part of a much broader project on the thermal stability of ternary carbides which is funded by an ARC Discovery-Project grant (DP0664586) and an ARC Linkage-International grant (LX0774743) for one of us (IML). Neutron beamtime at ISIS (RB920121) was provided by the Science and Technology Facilities Council together with financial support from an AMRFP grant and LIEF grant (LE0882725).

\section{REFERENCES}

${ }^{1}$ M.W. Barsoum, The $\mathrm{M}_{\mathrm{N}+1} \mathrm{AX}_{\mathrm{N}}$ Phases: A New Class of Solids: Thermodynamically Stable Nanolaminates, Prog. Solid State Chem. 28, 201-281 (2000).

${ }^{2}$ H.B. Zhang, Y.W. Bao and Y.C. Zhou, Current Status in Layered Ternary Carbide $\mathrm{Ti}_{3} \mathrm{SiC}_{2}$, A Review, J. Mater._Sci. Technol. 25, 1-38 (2009).

${ }^{3}$ M.W. Barsoum and T. El-Raghy, The MAX Phases: Unique New Carbide and Nitride Materials, Am. Sci. 89, 334-343 (2001).

${ }^{4}$ I.M. Low, Vickers Contact Damage of Micro-Layered $\mathrm{Ti}_{3} \mathrm{SiC}_{2}$, J. Europ. Ceram. Soc. 18, 709-713 (1998).

${ }^{5}$ I.M. Low, S.K. Lee, M.W. Barsoum and B.R. Lawn, Contact Hertzian Response of $\mathrm{Ti}_{3} \mathrm{SiC}_{2}$ Ceramics, J. Am. Ceram. Soc. 81, 225-228 (1998).

${ }^{6}$ I.M. Low, Z. Oo and K.E. Prince, Effect of Vacuum Annealing on the Phase Stability of $\mathrm{Ti}_{3} \mathrm{SiC}_{2}, J$. Am. Ceram. Soc. 90, 2610-14 (2007).

${ }^{7}$ I.M. Low, Depth-Profiling of Phase Composition in a Novel $\mathrm{Ti}_{3} \mathrm{SiC}_{2}-\mathrm{TiC}$ System with Graded Interfaces, Mater. Lett. 58, 927-32 (2004).

${ }^{8}$ Z. Oo, I.M. Low and B.H. O'Connor, Dynamic Study of the Thermal Stability of Impure $\mathrm{Ti}_{3} \mathrm{SiC}_{2}$ in Argon and Air by Neutron Diffraction, Physica B, 385-386, 499-501 (2006).

${ }^{9}$ W.K. Pang, I.M. Low, and Z.M. Sun, In-Situ High-Temperature Diffraction Study of Thermal Dissociation of $\mathrm{Ti}_{3} \mathrm{AlC}_{2}$ in Vacuum, $J$ Am. Ceram. Soc. In press.

${ }^{10}$ W. K. Pang, I.M. Low, B.H. O'Connor, A.J. Studer, V.K. Peterson, Z.M. Sun and J-P Palmquist, Comparison of Thermal Stability in MAX 211 and 312 Phases, J. Physics: Conference Series. In press.

${ }^{11}$ W. K. Pang, and I.M. Low, Diffraction study of Thermal Dissociation in the Ternary Ti-Al-C System, J. Aust. Ceram. Soc. 45, 39-43 (2009).

${ }^{12}$ W.K. Pang, I.M. Low, B.H. O'Connor, A.J. Studer, V.K. Peterson, Z.M. Sun, and J.-P. Palmquist, Effect of Vacuum Annealing on the Thermal Stability of $\mathrm{Ti}_{3} \mathrm{SiC}_{2} / \mathrm{TiC} / \mathrm{TiSi}_{2}$ Composites. J. Aust. Ceram. Soc. 45, 272-77 (2009).

${ }^{13}$ J.X. Chen, Y.C. Zhou, H.B. Zhang, D.T. Wan, and M.Y. Liu, Thermal Stability of $\mathrm{Ti}_{3} \mathrm{AlC}_{2} / \mathrm{Al}_{2} \mathrm{O}_{3}$ Composites in High Vacuum, Mater. Chem. Phys., 104, 109-112 (2007).

${ }^{14}$ X.H. Wang and Y.C. Zhou, Stability and Selective Oxidation of Aluminium in Nano-Laminate $\mathrm{Ti}_{3} \mathrm{AlC}_{2}$ Upon Heating in Argon, Chem. Mater. 15, 3716-3720 (2003)

${ }^{15}$ M.W. Barsoum and T. El-Raghy, Synthesis and Characterization of Remarkable Ceramic: $\mathrm{Ti}_{3} \mathrm{SiC}_{2}, J$. Am. Ceram. Soc. 79, 1953-56 (1996). 
${ }^{16}$ R. Radakrishnan, J.J. Williams and M. Akinc, Synthesis and High-Temperature Stability of $\mathrm{Ti}_{3} \mathrm{SiC}_{2}$, J. Alloys Compd. 285, 85-88 (1999).

${ }^{17}$ J. Emmerlich, D. Music, P. Eklund, O. Wilhelmsson, U. Jansson, J.M. Schneider, H. Högberg, and L. Hultman, Thermal Stability of $\mathrm{Ti}_{3} \mathrm{SiC}_{2}$ Thin Films, Acta Mater. 55, 1479-1488 (2007).

${ }^{18}$ S. Hull, R.I. Smith, W. David, A. Hannon, J. Mayers, and R. Cywinski, The POLARIS powder diffractometer at ISIS, Physica B, 180-181, 1000-1002 (1992).

${ }^{19}$ J.W. Cahn, Transformation Kinetics During Continuous Cooling, Acta Metallurgica 4, 572-575 (1956).

${ }^{20}$ www.veeco.com/library/Learning_Center/Growth_Information/Vapor_Pressure_Data_For_Selected_ Elements/index.aspx

${ }^{21}$ H.B. Callen, Thermodynamics and an Introduction to Thermostatistics, published by Wiley, 1985.

${ }^{22}$ B. Moller, J. Rarey, D. Ramjugernath, Estimation of the Vapour Pressure of Non-Electrolyte Organic Compounds via Group Contributions and Group Interactions, J. Mol. Liq., 143, 52-63 (2008).

${ }^{23}$ A.K. Jena, and M.C. Chaturvedi, Phase Transformations in Materials. Prentice Hall. pp. 243-47 (1992). 